\title{
Numerical analysis of vertical stress distribution in the direct shear box devices
}

\author{
Jurgis Medzvieckas ${ }^{1}$, Šarūnas Skuodis ${ }^{2}$, Danute Sližyte ${ }^{3}$ \\ Department of Reinforced Concrete Structures and Geotechnics, \\ Vilnius Gediminas Technical University, Vilnius, Lithuania \\ E-mail: ${ }^{3}$ danute.slizyte@vgtu.lt (corresponding author)
}

\begin{abstract}
When determining the soil strength parameters with direct shear box devices, the values of the parameters are influenced by devices construction. In assessing this effect, it is necessary to know the magnitude of the vertical stresses and the nature of the distribution in the shear plane. The soil shear resistance depends on the size of the vertical stresses and the nature of the distribution in the shear plane. These factors depend on the interaction of the soil with the vertical walls of the device, i.s. friction between the soil and the walls. At the beginning of the test, the vertical stresses on the shear plane will be lower than the added pressure at the top of the sample, however the stresses increases due to dilation during the test. Before the test ends, the stresses in the shear plane will be higher than at the top of the sample. The article has presented the nature of the vertical stresses distribution on a horizontal plane when using direct shear box device. The analysis was performed using the PLAXIS 3D software.
\end{abstract}

Keywords: direct shear, vertical stresses distribution.

\section{Introduction}

At present, the triaxial and direct shear tests are most widely using tests to determining shear strength parameters. Direct shear test as simple and relatively cheap it is using very often. During this test, a specimen is placed in a rigid square or circular shear box and shearing linear sliding of one-half of the shear box relative to the other. A specimen of soil is laterally restrained and sheared along mechanically formed horizontal plane while is subjected to vertical stress applied normal to that plane. The size of the normal stresses and the nature of the distribution in the shear plane affect the size of the tangential stresses. The soil shear strength is resistance to tangential stresses in the shear plane. The construction of the direct shear devices has an influence on the values of the soil strength parameter. As influencing factors can be sample size and interaction of the soil with device vertical walls (Bareither, Benson, \& Edil, 2008; Cerato \& Lutenegger, 2006; Moayed, Alibolandi, \& Alizadeh, 2017). The construction of the direct shear devices using in different countries varies. The most widely used devices with a mobile lower box. ISO 17892-10 (International Organization for Standardization, 2008) offer two construction models: one - shear box test apparatus, other - ring shear apparatus. In plane square or circular shear box is divided horizontally into two rigid halves. They shall form a square or circular prism with a smooth internal surface. The design shall allow shearing by a small, controlled vertical displacement without tilt. One-half of the shear box shall be able to move smoothly and parallel to the other half. The shear box should be designed for a specimen with a minimum initial height of $20 \mathrm{~mm}$. According to ISO $17892-10$ the ratio of the specimen width or diameter to height should not be less than 2,5 . The loading cap can tilt without jamming and be rigid and sufficiently large to transmit the vertical load uniformly to the specimen. The factors that influence the determination of the shear strength parameters are: the distribution of stresses in the shear plane, the friction between soil and devices walls and therefore not full vertical pressure added to the top of the sample is passed to the shear plane; horizontal displacement speed (Wu, Matsushima, \& Tatsuoka, 2008). It is generally accepted that the vertical pressure added to the top of the sample is transmitted completely to the cutting plane. However, friction forces are formed between the soil and the vertical walls of the device, the size of which depends on the size of the vertical pressure and the area of the contact surface. Friction between the soil and device walls affects the nature and size of the normal pressure distribution in the shearing plane (Kostkanova \& Herle, 2012; Liu, Sun, \& Matsuoka, 2005). The studies show that only $65-85 \%$ of the vertical pressure added on the top of the sample is transferred to the shearing plane (Amšiejus, Dirgèlienè, Norkus, \& Skuodis, 2014). When calculating soil strength parameters the normal stresses should be take in the shear plane. During the test, the dilation process takes place in the cutting plane (Simoni $\&$

(C) 2019 Authors. Published by VGTU Press. This is an open-access article distributed under the terms of the Creative Commons Attribution (http://creativecommons.org/licenses/by/4.0/) License, which permits unrestricted use, distribution, and reproduction in any medium, provided the original author and source are credited. 
Houlsby, 2006). Dilatancy is the volume change observed in the shear plane of the granular materials. In the dense soils, the dilatance influence is higher. When testing the soils, neither the upper nor the lower box can move vertically, so during the dilatation process, the volume changes will affect normal stresses acting in the shearing plane due to the friction between the soil and the device walls. In such type of devices the vertical stresses in the shearing plane increase due to dilation in the shear plane. Factors that will influence the shear strength parameters were approved of using numerical modeling methods (Jacobson, Valdes, \& Evans, 2007; Zhang \& Thornton, 2007).

\section{Analysis of the experimental data}

The experimental studies carried out confirm that not all vertical pressure added to the top of the sample is transmitted to the shearing plane. The tests were performed with a direct shear device in which the vertical pressure was measured on the lower ring (see Amšiejus, 2000). For the assessing the changes of vertical stresses in the shearing plane, the shear strength of the varying densities sands was determined by applying a constant pressure at the top of the sample and measured pressure on the lower ring (see Figure 1).

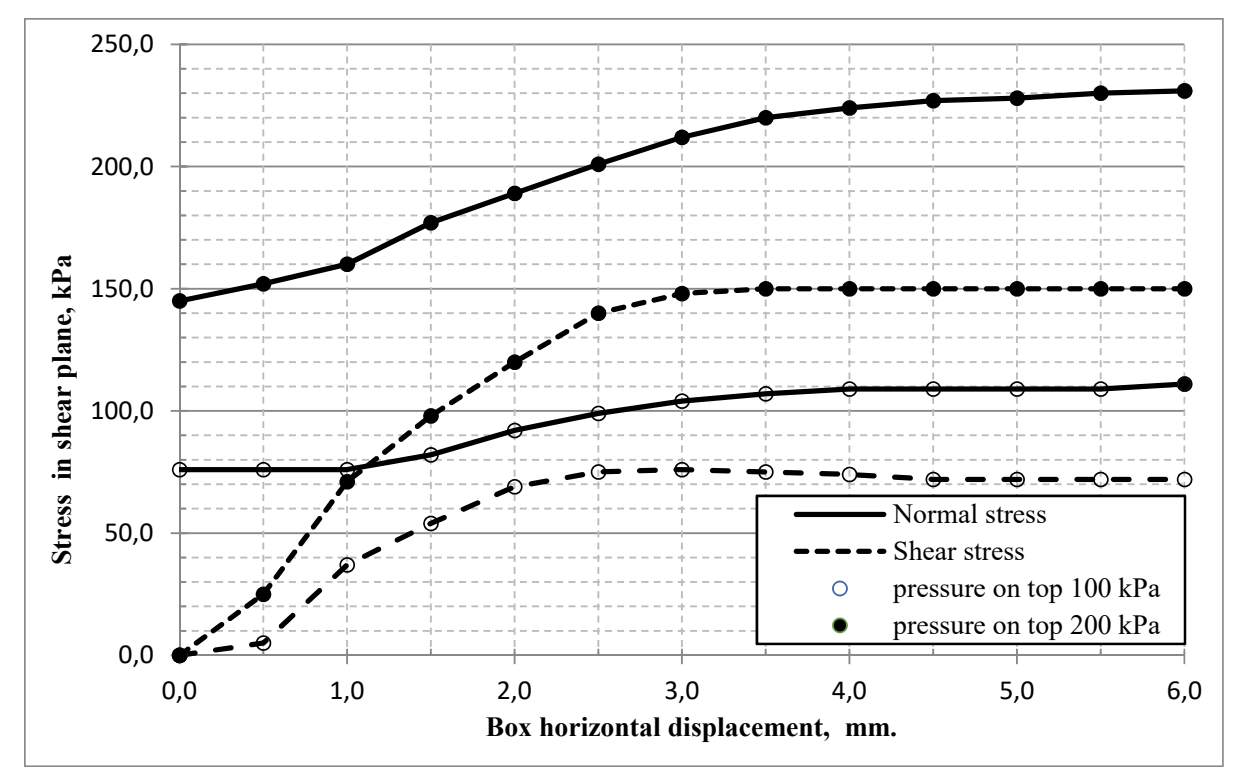

Figure 1. Stress distribution in the shear plane, when pressure on the sample top was $100 \mathrm{kPa}$ and $200 \mathrm{kPa}$ (see Amšiejus, 2000)

At the initial stage of the test, the vertical stresses in the shear plane will be lower than the pressure at the top of the sample, but the stresses increases due to dilatation during horizontal displacement of box. At the end of the test, the dilatation will result in higher stresses in the cutting plane than on the top of the sample.

\section{Numerical analysis of vertical stresses distribution in direct shear boxes horizontal plane}

In order to assess the influence of the device design, it is necessary to know the variations of normal stresses in the shear plane, when determining the soil shear strength parameters. It is necessary to know the size of the normal stresses and the nature of the distribution in the shear plane. The analysis was performed using the PLAXIS 3D software. Evaluating the nature of the stresses distribution was chosen Mohr-Coulomb model, soil - sand with friction angle $\varphi=36^{\circ}$, dilatancy angle $\psi=6^{\circ}$, cohesion $\mathrm{c}=1.0 \mathrm{kPa}$, unit weight $\gamma=18.0 \mathrm{kN} / \mathrm{m}^{3}$, Poisson's ratio $v=0.30$, Young's modulus $\mathrm{E}=20.0 \mathrm{MPa}$. The shear box has been accepted as circular or square metal hollow pile with soil inside. The cap had been accepted as thick metal plate loaded with distributed load. In Figure 2 and Figure 3 are shown the nature and size of normal stress distribution in horizontal planes at the top of the sample, $5 \mathrm{~mm}, 10 \mathrm{~mm}, 15 \mathrm{~mm}$ and $25 \mathrm{~mm}$ below in plan circular shear box when pressure under cap bottom equal $200 \mathrm{kPa}$. We assume that the pressure on the sample top is equal to the vertical force acting the cap divided by the shear box area. In Figure 2a is shown the normal stresses distribution nature when there are no gaps between the cap and in plan circular shear walls, that is to say, the cap edge is close to the wall. Interface Ri between the cap and shear box walls is accepted 0.5 between soil and shear box walls is the same. The interfaces are modeling the interaction between the surfaces, which are intermediate between smooth and fully rough $\left(R_{i}=1.0\right)$. The roughness of interaction is modeled by choosing a value for the strength reduction factors (wall friction or adhesion). In Figure $2 b$ is shown the nature and size of normal stresses distribution when between caps and circular in plan shear box walls is a small gap. It will be no interaction between the cap and shear box walls and $\mathrm{R}_{\mathrm{i}}=0.5$ between soil and shear box walls. 


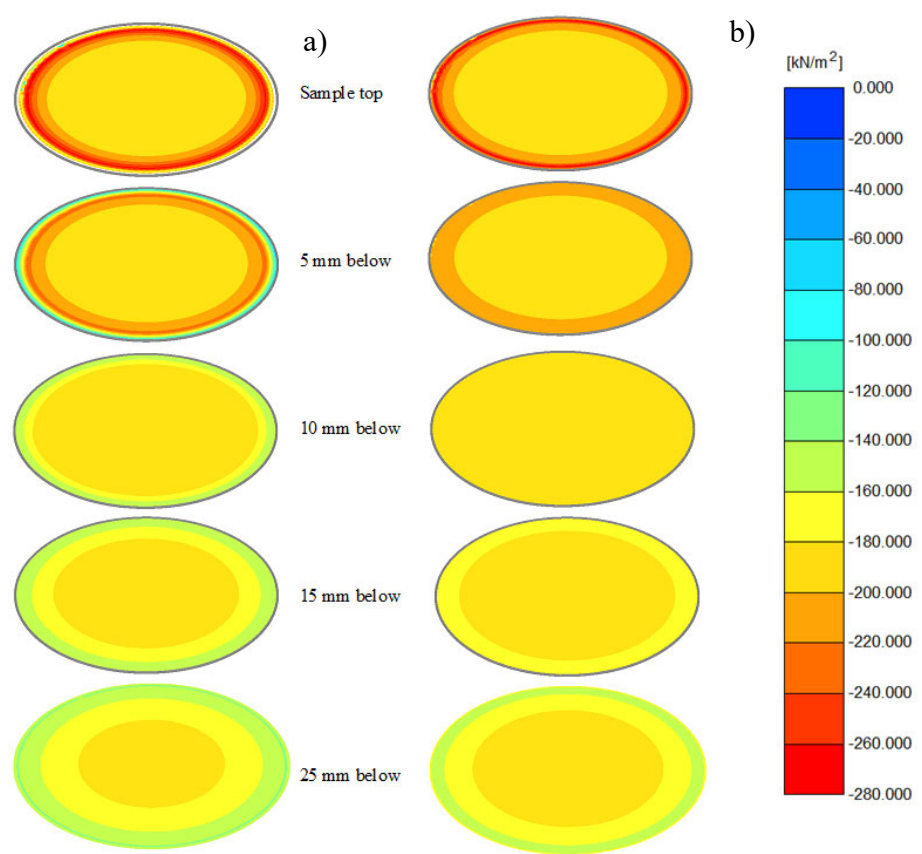

Figure 2. Nature and size of normal stresses distribution in the circular shear box:

a) no gaps between the cap and box walls; b) with a small gap between caps and box walls

In Figure 3a is shown the nature and size of the normal stress distribution when there are very small gaps between the cap and in the square in plane walls, interface strength reduction factors $R_{i}=0.5$ between the cap and shear box walls, same between soil and shear box walls. In Figure $3 \mathrm{~b}$ is shown the distribution of the normal stresses distribution and size when between the cap and walls there is a larger spacing of the several $\mathrm{mm}$. The interaction between soil and shear box walls is accepted $\mathrm{R}_{\mathrm{i}}=0.5$.

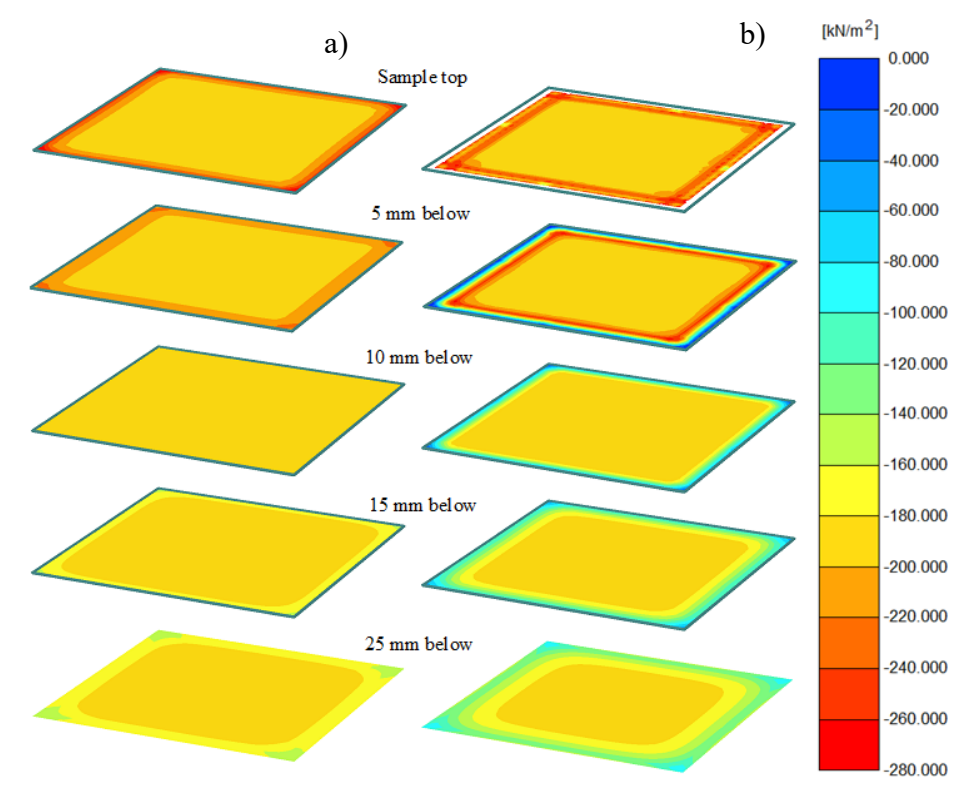

Figure 3. Nature and size of normal stresses distribution in the square shear box:

a) small gaps between the cap and box walls; b) with larger spacing between caps and box walls

Both in the circular shear box and in plan square devise the spacing between cap and wall will influence the nature of the stress distribution. In Figure $4 a$ interface $R_{i}$ is accepted 0.1 by choosing very smooth walls surface and small wall friction. In Figure $4 b$ interface $R_{i}$ is accepted 0.5 by choosing often applied friction strength reduction factors between soil and metal shear box walls. In Figure 4 and Figure 5 there are accepted small spacing between cap and wall. 


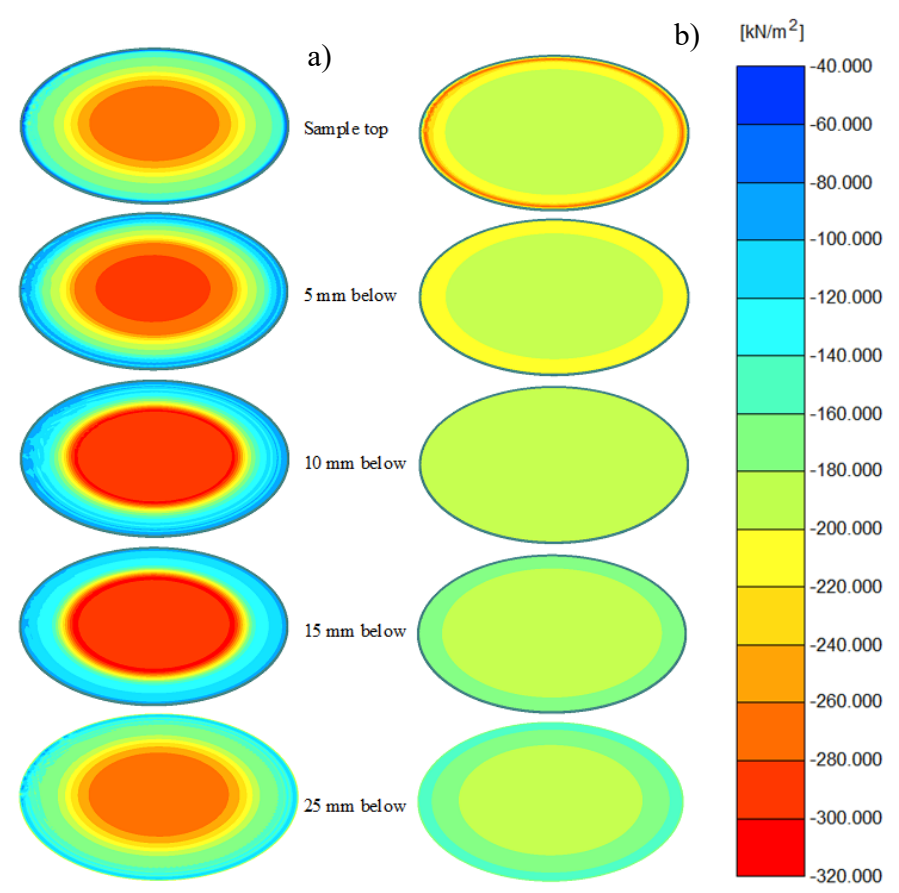

Figure 4. Nature and size of normal stresses distribution in circular shear box: a) interface $\left.R_{i}=0.1 ; b\right)$ interface $R_{i}=0.5$

In plan square shear box nature of stresses, distribution is similar. In Figure $5 \mathrm{a}$ is given stress distribution nature when $R_{i}=0.1$ in Figure $5 b$ interface $R_{i}=0.5$. The interaction between the wall surfaces and soil has a great influence on the nature of vertical stresses distribution and size, both in plan square and circular shear box devices.

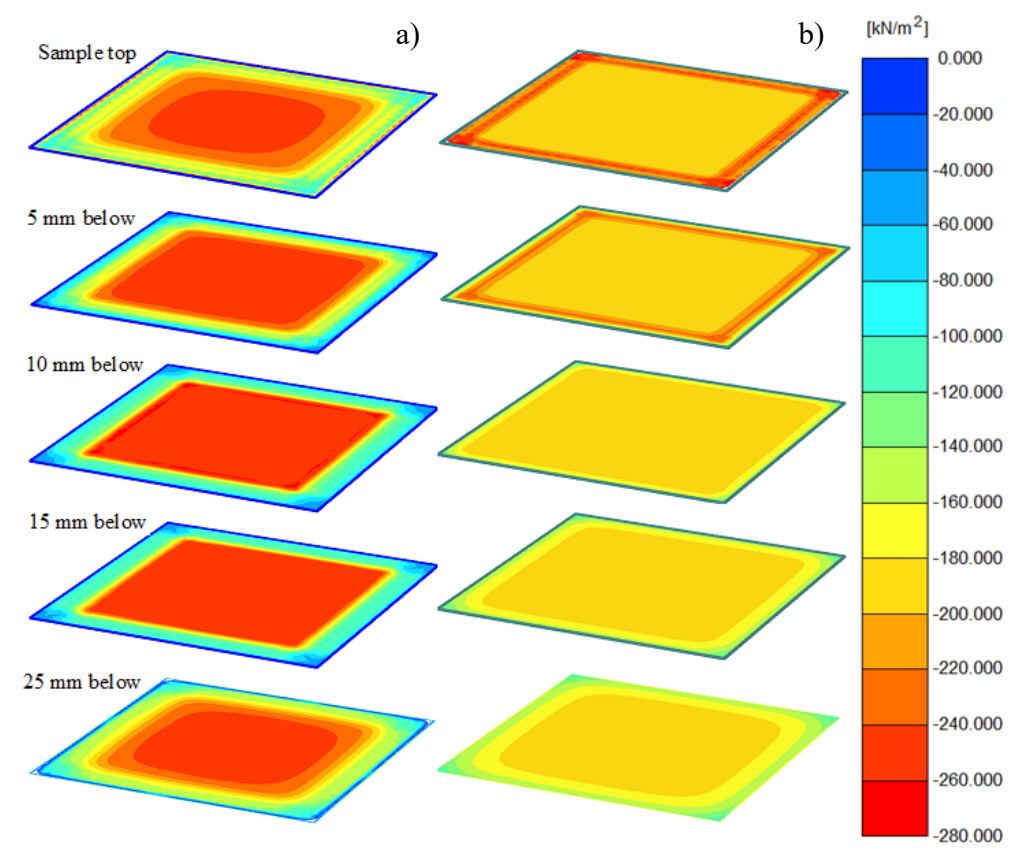

Figure 5. Nature and size of normal stresses distribution in square shear box: a) interface $\mathrm{R}_{\mathrm{i}}=0.1$; b) interface $\mathrm{R}_{\mathrm{i}}=0.5$

During the test, the dilation process takes place in the shear plane in the dense soils. In such soils, it is observed the volume changes. The soil continues to dilate as shear deformation take place. In most case, volume changes will occur until soil will reach a critical state at some point. The behaviour of strain localization in sand has been observed in laboratory tests (Tatsuoka, Nakamura, Huang, \& Tani, 1990). Zhao and Gao (2013) present a numerical study on strain localization in sand. The significant volumetric expansion has been noticed inside the shear band (Zhao \& Gao, 2013), which is in agreement with the experimental observations (Oda, Konishi, \& Nemat-Nasser, 1982). In Figure 6 is shown the volumetric strain localization zone, which was accepted in the calculations. 

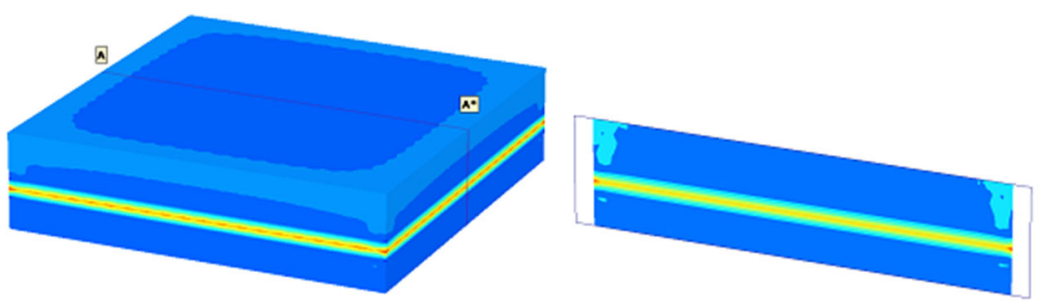

Figure 6. Volumetric strain localization in sample

In Figure 7 is shown the nature and size of the normal stresses distribution in the shear plan, when volumetric strain in the local shear zone is $0 \%-2 \%-3 \%-5 \%-7 \%$. The pressure on the sample top is accepted $200 \mathrm{kPa}$. Interface strength reduction factors between soil and shear box walls equal to 0.5 .

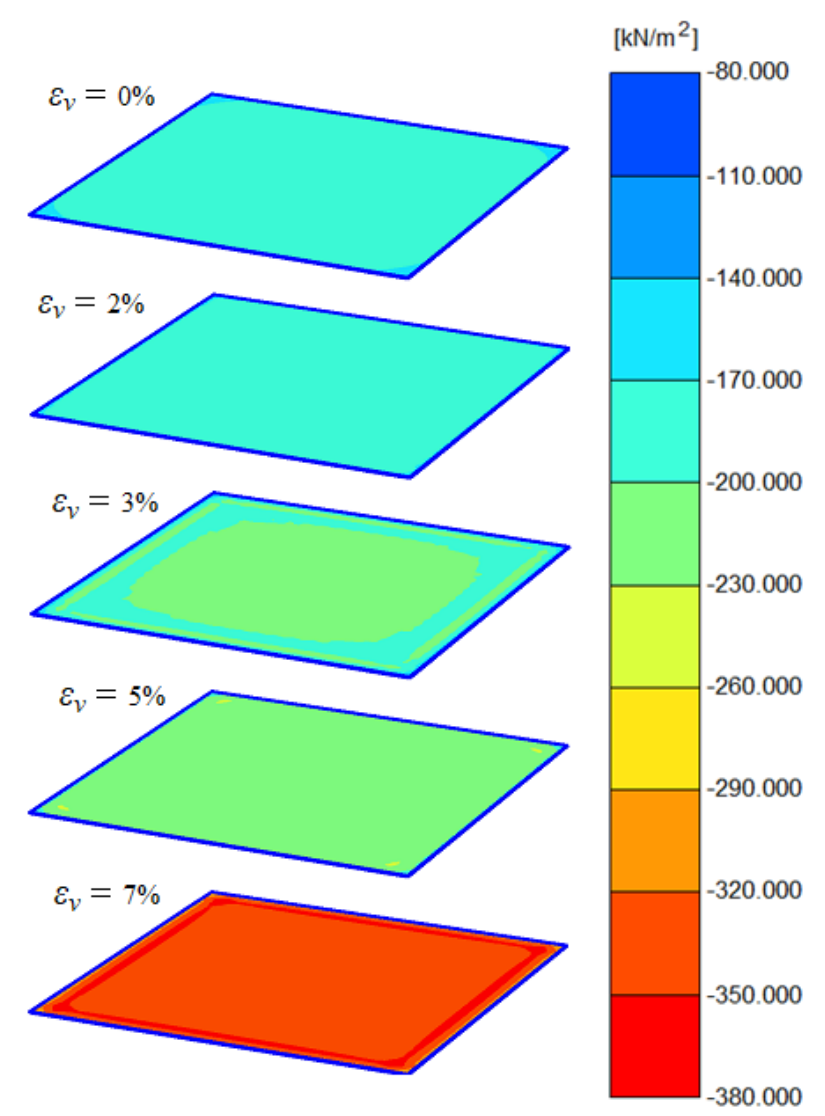

Figure 7. Nature and size of the normal stresses distribution in the shear plan, when volumetric strain in the local shear zone is $0 \%-2 \%-3 \%-5 \%-7 \%$

It can be seen that the nature and size of normal stresses distribution in shear plan begin to increase when volumetric strain is more than $2 \%$. At $3 \%$ in the larger part of the shear plane zone, the vertical stresses are greater than $200 \mathrm{kPa}$, at $5 \%$ in all shear plane the vertical stresses are over $230 \mathrm{kPa}$, at $7 \%$ in the shear plane the vertical stresses are over $320 \mathrm{kPa}$.

\section{Conclusions}

Numerical analysis of vertical stresses distribution performed using the PLAXIS 3D software shown that the gap between cap and shear box walls, the interaction between the walls surfaces and soil, volumetric strain in shear plan influence vertical stress influence distribution.

The size of the gap between cap and shear box walls influences on stress distribution nature close to the wall. The stresses on top close to walls are higher than nominal, deeper decreases and become smaller than the pressure on the top. Both in a square and a circular shear box $10 \mathrm{~mm}$ below the top, the pressure on the horizontal plane become equal to the nominal pressure $200 \mathrm{kPa}$ on the top. 
The greater influence on the stresses distribution nature and size are doing the interface (friction) between the soil and the walls of the device. When accepted negligible friction (strength reduction factor), the stresses are concentrating in the middle of the plane, stresses decrease near to the wall. When is a choice often applied friction strength reduction factor between metal surfaces and soil 0.5 , the stresses distribution nature is much more uniformed.

During the direct shear test, the dilatation process takes place in the shear plane in the dense soils. In the shear zone, it is observed the volume changes in the soil. The friction between soil and device walls increases the normal stresses in the shear plane. The particularly pronounced gain was observed when volumetric strain in the shear zone is greater than $5 \%$.

\section{Acknowledgements}

Equipment and infrastructure of Civil Engineering Scientific Research Centre of Vilnius Gediminas Technical University were employed for investigations.

\section{References}

Amšiejus, J. (2000). Determination design values of soil strength parameter (Summary of doctoral thesis, Vilnius Gediminas Technical University). Vilnius: Technika.

Amšiejus, J., Dirgèlienè, N., Norkus, A., \& Skuodis, Š. (2014). Comparison of sandy soil shear strength parameters obtained by various construction direct shear apparatuses. Archives of Civil and Mechanical Engineering, 14(2), 327-334. https://doi.org/10.1016/j.acme.2013.11.004

Bareither, C. A., Benson, C. H., \& Edil, T. B. (2008). Comparison of shear strenght of sand backfills measured in small-scale and large-scale direct shear tests. Canadian Geotechnical Journal, 45(9), 1224-1236. https://doi.org/10.1139/T08-058

Cerato, A. B., \& Lutenegger, A. J. (2006). Speciment size and scale effects of direct shear box tests of sands. Geotechnical Testing Journal, 29(6), 507-516. https://doi.org/10.1520/GTJ100312

International Organization for Standardization. (2018). Geotechnical investigation and testing - Laboratory testing of soil - Part 10: Direct shear tests (ISO 17892-10). Retrieved from https://www.iso.org/standard/72015.html

Jacobson, D. E., Valdes, J. R., \& Evans, T. M. (2007). A numerical view into direct shear specimen size effects. Geotechnical Testing Journal, 30(6), 512-516. https://doi.org/10.1520/GTJ100923

Kostkanova, V., \& Herle, I. (2012). Measurement of wall friction in direct shear tests on soft soil. Acta Geotechnica, 7(4), 333-342. https://doi.org/10.1007/s11440-012-0167-6

Liu, S. H., Sun, D. A., \& Matsuoka, H. (2005). On the interface friction in direct shear test. Computers and Geotechnics, 32(5), 317-325. https://doi.org/10.1016/j.compgeo.2005.05.002

Moayed, R. Z., Alibolandi, M., \& Alizadeh, A. (2017). Specimen size effects on direct shear test of silty sands. International Journal of Geotechnical Engineering, 11(2), 198-205.

Oda, M., Konishi, J., \& Nemat-Nasser, S. (1982). Experimental micromechanical evaluation of strength of granular materials: effect of particle rolling. Mechanics of Materials, 1(4), 269-283. https://doi.org/10.1016/0167-6636(82)90027-8

Simoni, A., \& Houlsby, G. T. (2006). The direct shear strength and dilatancy of sand-gravel mixtures. Geotechnical and Geological Engineering, 24(3), 523-549. https://doi.org/10.1007/s10706-004-5832-6

Tatsuoka, F., Nakamura, S., Huang, C. C., \& Tani, K. (1990). Strength anisotropy and shear band direction in plane strain tests of sand. Soils and Foundations, 30(1), 35-54. https://doi.org/10.3208/sandf1972.30.35

Wu, P., Matsushima, K., \& Tatsuoka, F. (2008). Effects of Specimen size and some other factors on the strength and deformation of granular soil in direct shear tests. Geotechnical Testing Journal, 31(1), 45-64. https://doi.org/10.1520/GTJ100773

Zhang, L., \& Thornton, C. (2007). A numerical examination of the direct shear test. Geotechnique, 57(4), 343-354. https://doi.org/10.1680/geot.2007.57.4.343

Zhao, J. D., \& Gao, Z. W. (2013). Strain localization and fabric evolution in sand. International Journal of Solids and Structures, 50(22-23), 3634-3648. https://doi.org/10.1016/j.ijsolstr.2013.07.005 